\title{
A hybrid evolutionary algorithm for distribution feeder reconfiguration
}

\author{
TAHER NIKNAM ${ }^{1, *}$, REZA KHORSHIDI $^{2}$ and \\ BAHMAN BAHMANI FIROUZI ${ }^{3}$
}

\author{
${ }^{1}$ Electronic and Electrical Engineering Department, Shiraz University of \\ Technology, Shiraz 71557 13961, Iran \\ ${ }^{2}$ Islamic Azad University, Fars Science and Research Branch 73715 18100, Iran \\ ${ }^{3}$ Islamic Azad University, MArvdasht Branch 73711 13119, Iran \\ e-mail: niknam@sutech.ac.ir; taher_nik@yahoo.com
}

MS received 24 April 2008; revised 29 December 2009; accepted 7 January 2010

\begin{abstract}
Distribution feeder reconfiguration (DFR) is formulated as a multiobjective optimization problem which minimizes real power losses, deviation of the node voltages and the number of switching operations and also balances the loads on the feeders. In the proposed method, the distance ( $\lambda_{2}$ norm) between the vectorvalued objective function and the worst-case vector-valued objective function in the feasible set is maximized. In the algorithm, the status of tie and sectionalizing switches are considered as the control variables. The proposed DFR problem is a non-differentiable optimization problem. Therefore, a new hybrid evolutionary algorithm based on combination of fuzzy adaptive particle swarm optimization (FAPSO) and ant colony optimization (ACO), called HFAPSO, is proposed to solve it. The performance of HFAPSO is evaluated and compared with other methods such as genetic algorithm (GA), ACO, the original PSO, Hybrid PSO and ACO (HPSO) considering different distribution test systems.
\end{abstract}

Keywords. Ant colony optimization (ACO); distribution feeder reconfiguration; fuzzy adaptive particle swarm optimization (FAPSO).

\section{Introduction}

Radial configuration is popular in distribution networks because of the effective coordination between feeder's protection systems and lower short circuit currents. Distribution feeders have two types of switches: normally closed (sectionalizing) switches and normally opened (tie) switches (Augugliaro et al 2003; Kim \& Ko 1993; Chiou \& Wang 1999; Chiou \& Chang 2005; Delbem et al 2005; Gomes \& Carneiro 2005). The configuration of the distribution feeders can be changed by opening sectionalizing switches and closing tie switches in such a way that the network remains radial with all of the loads being supplied. Reconfiguration

*For correspondence 
can also decrease power losses, increase system security, enhance power quality, and prevent overloading of the network components. DFR is defined as altering the topological structure of the distribution feeders by changing the open/close status of sectionalizing and tie switches based on the solution of an optimization problem (Taleski \& Rajicic 1997; Tzong \& Lee 2003; Zhou et al 1997). Since the status of the switches is non-differentiable, the corresponding optimization problem is complex, nonlinear, and combinatorial (Zhou et al 1997).

In recent years, many researchers have investigated the loss minimization problem in distribution networks. First of all, Merlin \& Back (1975) proposed an approach for distribution feeder reconfiguration by minimizing power losses as an objective function. They used branch and bound method to determine the optimal configuration that provides minimal loss for a distribution system with a spanning tree structure at a specific load. There is a vast literature on employing other methods to solve this problem. For instance, a heuristic method for the reconfiguration of distribution networks has been proposed by Shirmohammadi \& Hong (1989). They reduced the resistive line losses under normal operating conditions. Civanlar et al (1988) heuristically determined a distribution system configuration which reduces the line losses. A heuristic constructive algorithm has been proposed by McDermott et al (1999). The algorithm starts with all maneuverable switches open, and at each step, the switch that results in the least increase in the objective function is closed. The objective function was defined as the incremental losses divided by the incremental load served. Lopez \& Opaso (2004) presented an algorithm for online reconfiguration evaluation in power networks which deals with actual applications, considers a different load patterns, and analyses reconfiguration hourly. A refined genetic algorithm was presented by Zhu (2002) to find a distribution feeder configuration that reduces losses. The method described by Vanderson et al (2005), combines two heuristic procedures for determining the group of switches that should be opened in order to minimize the total power losses in distribution systems. These authors (Hsiao \& Chien 2001; Debaprya 2006; Huang 2002; Prasad \& Ranjan 2005) combined the optimization techniques with heuristic rules and fuzzy logic to achieve higher efficiency and robust performance. Baran \& $\mathrm{Wu}(1989)$ made an attempt to improve the method of Civanlar et al (1988) by introducing two approximation formulae for power flow of system load.

Conventional optimization methods are not suitable for the DFR problem, which is a multiobjective optimization problem (Olamaei et al 2008). Elements of the vector-valued objective function are: the real power losses, the number of switching operations, and deviation of the bus voltages. In addition, loads on the feeders should be balanced. In order to find an optimal solution, distance between the current vector of the objective function, obtained from the current configuration of the network, and the worst-case vector of the objective function is maximized. Control variables are the status of the tie and sectionalizing switches. Since the configuration of the distribution system should remain radial, when a tie switch is closed, one sectionalizing switch must be opened to prevent loop formation. Thus, the number of control variables is twice the number of the tie switches. DFR is a nonlinear and non-differentiable optimization problem and therefore, evolutionary methods, which are independent of the structure of the problem as well as the type of the objective function and constraints, are the methods suitable for finding the global optima. This paper represents a novel hybrid evolutionary optimization algorithm to solve DFR problem, based on FAPSO and ACO, called HFAPSO.

The main contributions of the paper include: (i) a new approach for multi-objective DFR problem and (ii) presents a new hybrid evolutionary optimization algorithm to solve the DFR problem. The paper is classified as follows: In section 2, the proposed DFR is formulated. Section 3 introduces the basic principles of the PSO and fuzzy adaptive PSO algorithms. 
In section 4, the ACO algorithm is explained. In section 5, the HFAPSO is applied to solve the DFR problem. Section 6 deals with the feasibility of the HFAPSO method. In this section, the proposed DFR is demonstrated and its results are compared with those of other evolutionary methods such as genetic algorithm (GA), ACO, the original PSO and HPSO, over different distribution test systems. Finally, the conclusion is given in section 7 .

\section{Distribution feeder reconfiguration problem}

The related formulation of the proposed distribution feeder reconfiguration is developed as mentioned below.

\subsection{Objective function}

With the proposed DFR, the objective function consists of four terms: (i) Total active power losses; (ii) Load balancing among the feeders; (iii) Number of switching operations; and (iv) Deviation of the bus voltages. Objective functions are described as:

2.1a Minimization of the power losses: Minimization of the real power loss over the feeders is chosen as the first objective for the feeder reconfiguration since reducing the real power loss of the distribution feeders is a main goal in feeder reconfiguration. Minimization of the total real power losses over the feeders can be calculated as:

$$
\begin{aligned}
f_{1}(X) & =\sum_{i=1}^{N_{b r}} R_{i} \times\left|I_{i}\right|^{2}, \\
X & =\left[\mathrm{Tie}_{1}, \mathrm{Tie}_{2}, \ldots, \mathrm{Tie}_{N_{\text {tie }}}, S w_{1}, S w_{2}, \ldots, S w_{N_{\text {tie }}}\right],
\end{aligned}
$$

where $R_{i}$ and $I_{i}$ are resistance and actual current of the $i^{\text {th }}$ branch, respectively. $N_{b r}$ is the number of the branches. $X$ is the control variable vector. Tie $i_{i}$ is the state of the $i^{\text {th }}$ tie switch ( 0 and 1 correspond to open and close states, respectively). $S w_{i}$ is the sectionalizing switch number that forms a loop with $\mathrm{Tie}_{i} . N_{\text {tie }}$ is the number of tie switches.

2.1b Minimization of the deviation of the bus voltages: Bus voltages are one the most significant security and service quality indices, which can be described as:

$$
f_{2}(X)=\max _{i}\left|V_{i}-V_{\text {rate }}\right|, \quad i=1,2,3, \ldots, N_{\text {bus }},
$$

where $N_{\text {bus }}$ is total number of the buses. $V_{i}$ and $V_{\text {rate }}$ are the real and rated voltages on the $i^{\text {th }}$ bus, respectively.

2.1c Minimizing the number of switching operation: Minimizing the number of switching operations can be modelled as:

$$
f_{3}(X)=\sum_{i=1}^{N_{s}}\left|S_{i}-S_{o i}\right|,
$$

where $S_{i}$ and $S_{o, i}$ are the new and original states of the switch $i$, respectively. $N_{s}$ is the number of switches. 
2.1d Load balancing over the feeders: Load balancing is one of the major objectives in feeder reconfiguration. An effective strategy to increase the loading margin of heavily loaded feeders is to transfer a part of their loads to lightly loaded feeders. Load balancing over the feeders can be described as:

$$
f_{4}(X)=-\min _{i}\left|I_{i, \text { rate }}-I_{i}\right|, i=1,2,3, \ldots, N_{b r},
$$

where $I_{i}$ and $I_{i \text {,rate }}$ are the actual loading and the rated currents of the $i^{\text {th }}$ branch, respectively.

\section{2 formulation of the distribution feeder reconfiguration based on norm 2}

Formulation of the multi-objective distribution feeder reconfiguration including the mentioned objective functions can be written as:

$$
\begin{aligned}
\max J(X) & =\left\|f(X)-f_{0}\right\|_{2} \\
& =\sqrt{\left(f_{1}(X)-f_{o 1}\right)^{2}+\left(f_{2}(X)-f_{o 2}\right)^{2}+\left(f_{3}(X)-f_{o 3}\right)^{2}+\left(f_{4}(X)-f_{o 4}\right)^{2}} \\
f(X) & =\left[\begin{array}{l}
f_{1}(X) \\
f_{2}(X) \\
f_{3}(X) \\
f_{4}(X)
\end{array}\right], \quad f_{0}=\left[\begin{array}{l}
f_{01} \\
f_{02} \\
f_{03} \\
f_{04}
\end{array}\right],
\end{aligned}
$$

where $f_{01}$ and $f_{02}$ are respectively the real power loss and the maximum voltage deviation before reconfiguration, $f_{03}$ is the worst switching operation, which is $2 * N_{\text {tie }}$, and $f_{04}$ is the worst load balancing before reconfiguration.

$f(X)$ and $f_{0}$ are the vector value of the objective function at point $X$ and its corresponding worst case, respectively.

\subsection{Constraints}

The constraints are:

(i) Distribution line limits

$$
\left|P_{i j}^{\text {Line }}\right|<P_{i j, \text { max }}^{\text {Line }}
$$

$\left|P_{i j}^{\mathrm{Line}}\right|$ and $P_{i j, \max }^{\mathrm{Line}}$ are the absolute power and its corresponding maximum allowable value flowing over the distribution lines between the nodes $i$ and $j$, respectively.

(ii) Distribution power flow equations

$$
\begin{aligned}
P_{i} & =\sum_{i=1}^{N_{\text {bus }}} V_{i} V_{j} Y_{i j} \cos \left(\theta_{i j}-\delta_{i}+\delta_{j}\right), \\
Q_{i} & =\sum_{i=1}^{N_{\text {bus }}} V_{i} V_{j} Y_{i j} \sin \left(\theta_{i j}-\delta_{i}+\delta_{j}\right),
\end{aligned}
$$

where, $P_{i}$ and $Q_{i}$ are injected active and reactive power components at the $i^{\text {th }}$ bus on the network. $V_{i}$ and $\delta_{i}$ are respectively the amplitude and angle of the voltage at the $i^{\text {th }}$ bus. $Y_{i j}$ and $\theta_{i j}$ are the respective amplitude and angle of the branch admittance between the $i^{\text {th }}$ and $j^{\text {th }}$ buses. 


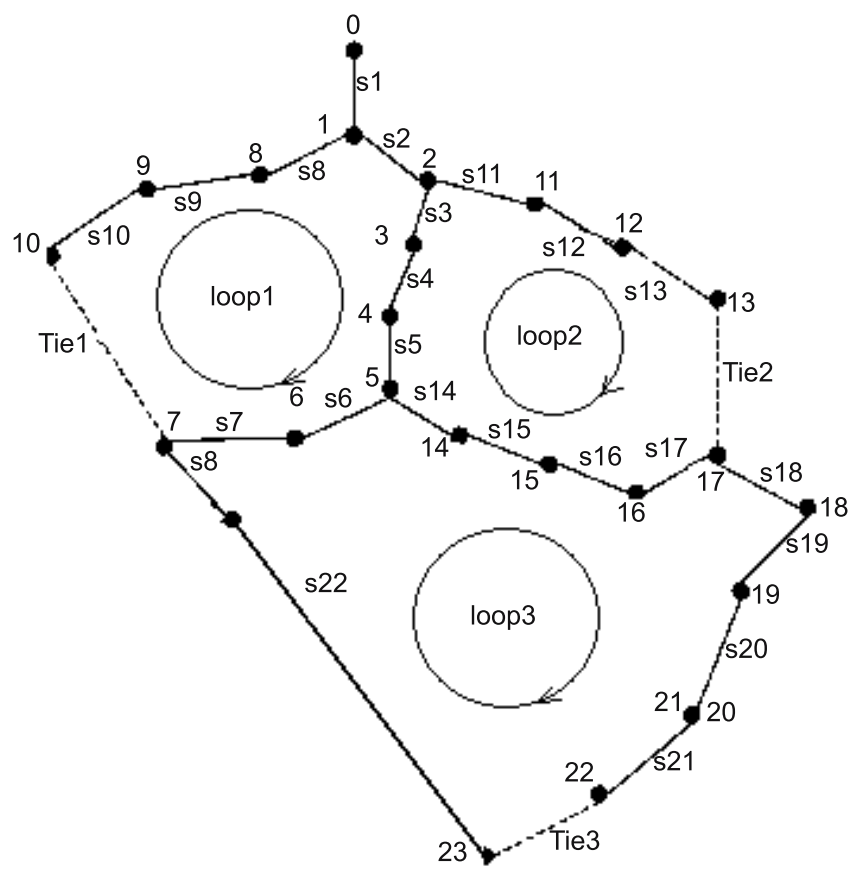

Figure 1. A radial distribution network.

(iii) Objective function limit

$$
f_{i}(X) \leq f_{0 i} \quad i=1,2,3,4 .
$$

(iv) Radial structure of the network.

In this paper, the main closed loops of the system are used to check the radial structure of the network. The number of main loops is calculated as:

$$
N_{F l}=N_{b r}-N_{\text {bus }}+1,
$$

where $N_{F l}$ is the number of main loops. It is noted that each main loop includes a tie switch and corresponding section switches that form a loop as shown in figure 1 . To retain a radial network structure, when a tie switch is closed, only one section switch is opened in each loop.

For example, the vector $X$ is defined as follows:

$$
\begin{aligned}
X & =\left[\mathrm{Tie}_{1}, \mathrm{Tie}_{2}, \mathrm{Tie}_{3}, S w_{1}, S w_{2}, S w_{3}\right] \\
& =[1,1,1,9,6,12]
\end{aligned}
$$

or

$$
\begin{aligned}
X & =\left[\mathrm{Tie}_{1}, \mathrm{Tie}_{2}, \mathrm{Tie}_{3}, S w_{1}, S w_{2}, S w_{3}\right] \\
& =[1,0,1,9,0,12] .
\end{aligned}
$$

In (13), since all the tie switches have been closed, sectionalizing switches \#9(loop1), \#6(loop2) and \#12(loop3) should be opened to maintain radial structure of the network. Considering (14), as tie \#2 is open, none of the sectionalizing switches should be opened $\left(S w_{2}=0\right)$. 


\section{Original PSO algorithm}

\subsection{Original PSO algorithm}

Particle swarm optimization (PSO) is a new evolutionary computation technique, which was introduced by Kennedy \& Eberhart (1995). It is inspired from the collective behaviour of social animals such as a flock of birds, a school of fish or a group of people that pursue a common goal in their lives. In this algorithm, each individual is referred to as a particle and presents a candidate solution of the optimization problem. Unlike other populationbased methodologies, every agent moves along its velocity vector, which is updated using two different best experiences; one is the best experience, which a particle has gained itself during the search procedure and the other is the best experience gained by the whole group. Combination of these experiences provides useful information for each particle to explore new positions in the domain of the problem.

In recent years, PSO has been extensively applied to solve problems related to power systems mainly because of its fast converging characteristics (Eberhart \& Shi 2001; Esmin et al 2005; Gaing 2003; Gaing 2004; Hong \& Hu 2005). Esmin et al (2005) discussed a method to handle discrete variables in PSO algorithm in order to optimize reactive power and voltage control. PSO is superior to Taboo Search method in terms of convergence time and solution quality. Application of PSO in economic dispatch problem has been addressed in (Niknam 2010). The maximum ramp up and down rates of the generators have been taken into account in the optimization problem (Gaing 2003). Also, comparison of results obtained by PSO and GA confirmed the superiority of PSO. Finally, optimum design of a PID controller in an AVR system using PSO technique is described in Gaing (2004). In the following the basic concept of the original PSO is presented.

In an $n$-dimensional search space, let the position and velocity of the $i^{\text {th }}$ individual be $X_{i}=\left(x_{i 1}, \ldots, x_{i d}, \ldots, x_{i n}\right)$ and $V_{i}=\left(v_{i 1}, \ldots, v_{i d}, \ldots, v_{i n}\right)$, respectively. The best previous experience of the $i$ th particle is recorded and represented by Pbest $_{i}=\left(\right.$ pbest $_{i 1}, \ldots$, pbest $_{i d}, \ldots$, pbest $\left._{i n}\right)$. The best global position of the swarm found so far is denoted by Gbest $_{i}=\left(\right.$ gbest $_{1}, \ldots$, gbest $_{d}, \ldots$, gbest $\left._{n}\right)$. The modified velocity of each particle is calculated considering the personal initial velocity, the distance from personal (local) best position, and the distance from global best position as expressed by equation (12).

$V_{i}^{(t+1)}=\omega \cdot V_{i}^{(t)}+c_{1} \cdot \operatorname{rand}_{1}(\mathrm{\circ}) \cdot\left(\right.$ Pbest $_{i}-X_{i}^{(t)}+c_{2} \cdot \operatorname{rand}_{2}(\mathrm{\circ}) \cdot\left(\right.$ Gbest $\left.-X_{i}^{(t)}\right)$.

Equation (12) determines the direction that the $i^{\text {th }}$ particle should take. Therefore, the new position of that particle can be determined by applying equation (13).

$$
X_{i}^{(t+1)}=X_{i}^{(t)}+V_{i}^{(t+1)} .
$$

In these equations, $i=1,2, \ldots, N$ is the index of each particle, $t$ is the iteration number, $\operatorname{rand}_{1}(\mathrm{O})$ and $\operatorname{rand}_{2}(\mathrm{O})$ are random numbers between 0 and $1 . N$ is the number of swarms. Constants $c_{1}$ and $c_{2}$ are weighting factors of the random acceleration terms, which pull each particle towards Pbest and Gbest positions. While low values allow particles to move away from the target region before they are pulled back, high values result in sharp movements toward the target region. The learning factors $c_{1}$ and $c_{2}$ are often set to 2.0 according to early experiences. In (Niknam \& Amiri 2010), authors have introduced the parameter $\omega$ into the PSO's equation to improve its performance. The appropriate selection of inertia weight $\omega$ in (12) provides a balance between global and local explorations, requiring less iteration 


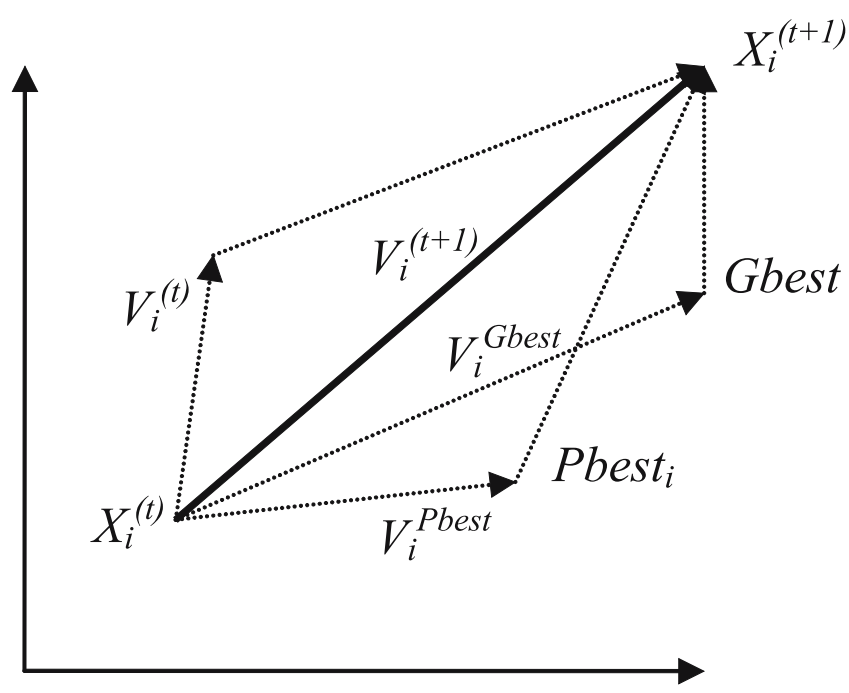

Figure 2. Concept of searching by PSO.

on average to find an optimal solution. As originally developed, $\omega$ often decreases linearly from 0.9 to 0.4 during a run. The inertia weight $\omega$ is typically set according to the following equation (Niknam 2010):

$$
\omega^{(t+1)}=\omega^{\max }-\frac{\omega^{\max }-\omega^{\min }}{t_{\max }} \times t .
$$

In equation (14), $t_{\max }$ is the maximum number of iterations and $t$ is the current iteration number. $\omega_{\max }$ and $\omega_{\min }$ are maximum and minimum of the inertia weights, respectively. Figure 2 shows the basic idea of the particle swarm optimizer.

As shown in equations (12) and (13), in the original PSO there are three parameters $\left(c_{1}, c_{2}\right.$ and $\omega$ ) that have a great influence on the performance of PSO. It may be impractical to get a unique set of parameters that work well in all cases. In this paper, a fuzzy adaptive PSO (FAPSO) algorithm has been utilized to find the values of the parameters based on a fuzzy system, as shown in the following.

\subsection{Fuzzy adaptive PSO(FAPSO) algorithm}

From experiences, it is known that (Niknam \& Amiri 2010):

(i) low inertia weight and high learning factors are often used when the value of the objective function is low at the end of the run (in the optimization of a minimum function)

(ii) high inertia and low learning factors should be used when the best fitness is stuck at one value for a long time.

So, the inertia weight and learning factors are evaluated using a fuzzy system. In the fuzzy system, the best fitness $(B F)$ and the number of generations for the best unchanged fitness $(N U)$ are considered as the input variables, while the inertia weight $(\omega)$ and learning factors $\left(c_{1}\right.$ and $\left.c_{2}\right)$ are considered as output variables.

The $B F$ value is the best solution found so far. As FAPSO algorithm should be applicable to a wide range of problems, the ranges of the $B F$ and $N U$ values should be normalized into 

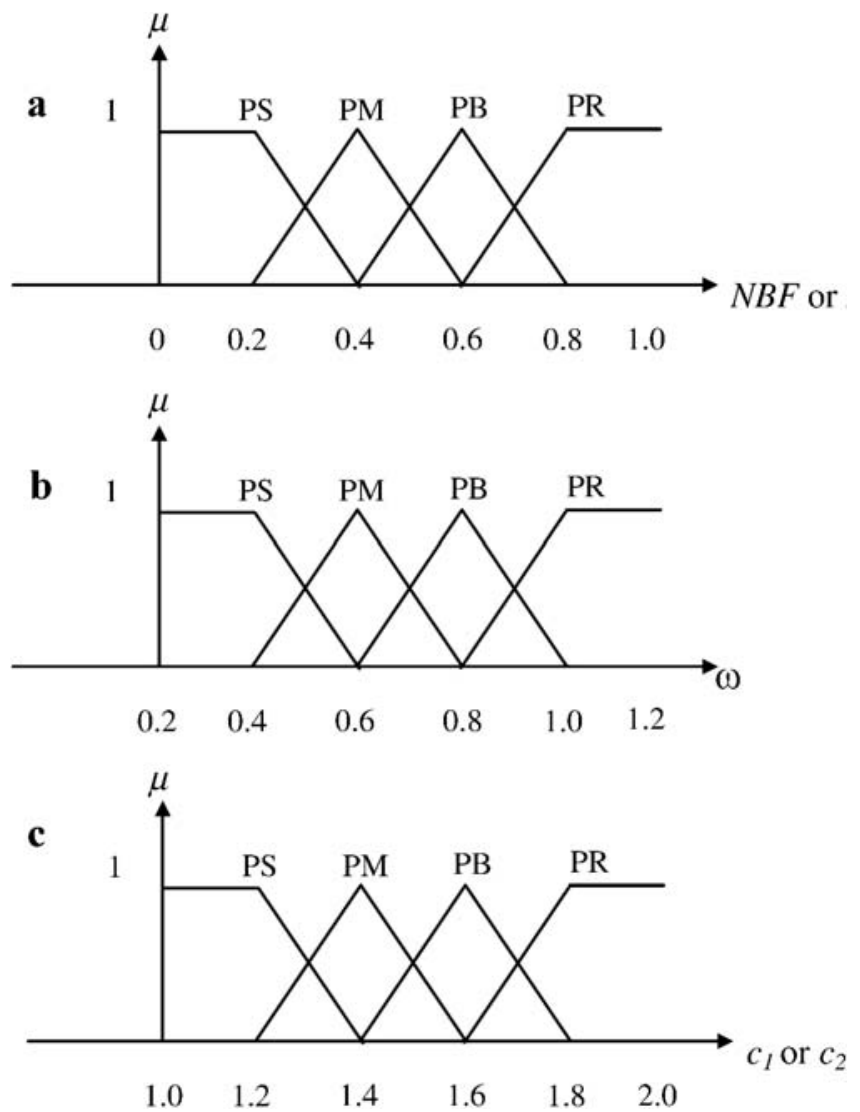

Figure 3. Membership functions of inputs and outputs (a) NBF or $\mathrm{NU}$, (b) $\omega$, and (c) $c_{1}$ and $c_{2}$.

$[0,1 \cdot 0]$. An example of converting the $B F$ value to be a normalized $B F$ format $(N B F)$ is shown in (15):

$$
N B F=\frac{B F-B F_{\min }}{B F_{\max }-B F_{\min }},
$$

where, $B F_{\max }$ and $B F_{\min }$ are the maximum and minimum values of $B F$ value, respectively.

$N U$ can be normalized into $[0,1 \cdot 0]$ in similar way.

The membership functions of inputs and outputs have been shown in figure 3 .

In figure 3 PS (positive small), PM (positive medium), PB (positive big) and PR (positive bigger) are the linguist variables for the inputs and outputs.

The Mamdani-type fuzzy rule base is used to formulate the conditional statements which comprise fuzzy logic. For example,

$R_{i}$ : IF (NBF is $\left.\mathrm{PB}\right)$ and (NU is $\left.\mathrm{PM}\right)$,

THEN ( $\omega$ is $\mathrm{PB}),\left(c_{1}\right.$ is $\left.\mathrm{PM}\right)$ and $\left(c_{2}\right.$ is $\left.\mathrm{PM}\right)$.

Tables 1 to 3 (Niknam 2010) show the fuzzy rules to evaluate the inertia weight $(\omega)$ and learning factors $\left(c_{1}\right.$ and $\left.c_{2}\right)$, respectively.

To obtain a deterministic control action, a defuzzification strategy is required. In this paper, the centroid method has been used. 
Table 1. Fuzzy rules for the inertia weight.

\begin{tabular}{llllll}
\hline & & \multicolumn{4}{c}{ NU } \\
\cline { 3 - 6 }$\omega$ & & PS & PM & PB & PR \\
\hline NBF & PS & PS & PM & PB & PB \\
& PM & PM & PM & PB & PR \\
& PB & PB & PB & PB & PR \\
& PR & PB & PB & PR & PR \\
\hline
\end{tabular}

Table 2. Fuzzy rules for learning factor $c_{1}$.

\begin{tabular}{llllll}
\hline & & \multicolumn{4}{c}{ NU } \\
\cline { 3 - 6 }$\omega$ & & PS & PM & PB & PR \\
\hline NBF & PS & PR & PB & PB & PB \\
& PM & PB & PM & PM & PS \\
& PB & PB & PM & PS & PS \\
& PR & PM & PM & PS & PS \\
\hline
\end{tabular}

\section{Ant colony optimization method}

Dorigo and his colleagues proposed Ant colony algorithms as a multi-agent approach to solve difficult combinatorial optimization problems such as the travelling salesman problem (TSP) and the quadratic assignment problem (QAP) (Dorigo et al 1999; Niknam et al 2005a; Niknam et al 2005b). Also, ant colony has been applied to solve problems such as unit commitment, economic dispatch, reactive power pricing in restructured networks, Vol/Var control in distribution networks, etc. (Niknam 2008; Niknam et al 2005a; Niknam et al 2005b).

Ants are social insects. Since they are blind animals, they find the shortest path from nest to food using pheromone. Pheromone is a chemical material deposited by ants along the path and serves as a critical communication media among them. Ants find the shortest path based on the intensity of pheromone deposited on different paths (Niknam 2008; Niknam et al 2005a; Niknam et al 2005b). In order to realize better, assume that ants want to move from point A to B (figure 4).

Table 3. Fuzzy rules for learning factor $c_{2}$.

\begin{tabular}{llllll}
\hline & & \multicolumn{4}{c}{ NU } \\
\cline { 3 - 5 }$\omega$ & & PS & PM & PB & PR \\
\hline NBF & PS & PR & PB & PM & PM \\
& PM & PB & PM & PS & PS \\
& PB & PM & PM & PS & PS \\
& PR & PM & PS & PS & PS \\
\hline
\end{tabular}




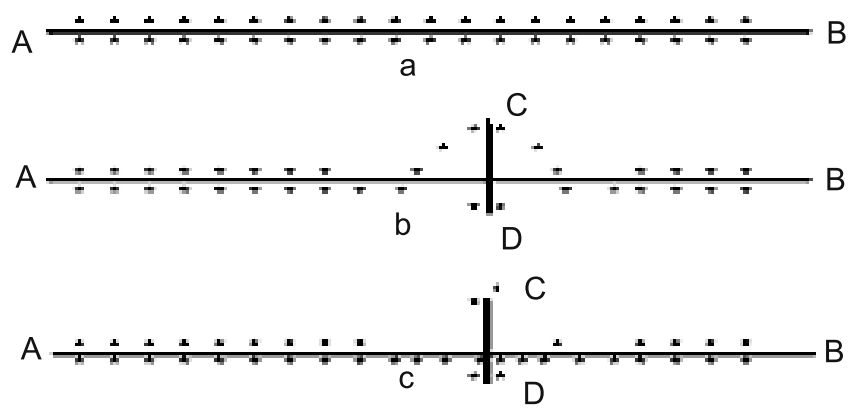

Figure 4. An example of finding the shortest path by ants.

If there is no obstacle, all of them will move along the straight path (AB) (figure 4a). Now assume that there is an obstacle on their way. In this case, ants will not be able to follow the original trial. Therefore, they turn to left (ACB) and right (ADB), randomly (figure 4b). Since ADB path is shorter than ACB, the intensity of pheromone deposited on ADB is more than the other path and ants will increasingly take the shorter path (figure $4 \mathrm{c}$ ). This behaviour forms the fundamental paradigm of ant colony method.

As it was indicated in figure 4, the intensity of deposited pheromone is one of the most important factors for ants to find the shortest path. Therefore, this factor plays a key role in simulating the behaviour of ants. Generally, the following factors are used to simulate ant systems:

- Intensity of pheromone

- Length of the path.

To select the next path, the state transition probability is defined as follows:

$$
P_{i j}=\frac{\left(\tau_{i j}\right)^{\gamma_{2}}\left(1 / L_{i j}\right)^{\gamma_{1}}}{\sum_{\substack{j=1 \\ j \neq i}}^{N A}\left(\tau_{i j}\right)^{\gamma_{2}}\left(1 / L_{i j}\right)^{\gamma_{1}}},
$$

where $\tau_{i j}$ and $L_{i j}$ are the intensity of pheromone and length of the path between nodes $j$ and $i$, respectively. $\gamma_{1}$ and $\gamma_{2}$ are control parameters for determining the weight of trail intensity and length of the path, respectively. $N A$ is the number of ants.

After selecting the next path, trail intensity of pheromone is updated as:

$$
\tau_{i j}(k+1)=\rho \tau_{i j}(k)+\Delta \tau_{i j} .
$$

In the above equation, $\rho$ is a coefficient and $(1-\rho)$ represents the evaporation of trail between time $k$ and $k+1$ and $\Delta \tau_{i j}$ is the amount of pheromone trail added to $\tau_{i j}$ by ants.

\section{HPSO application in distribution feeder reconfiguration}

As mentioned in the previous sections, the studies done by the researchers confirm that the PSO method is a powerful and efficient technique to deal with nonlinear optimization problems. However, it may be trapped in local optima if global and local best positions are equal to the position of a particle over a number of iterations. 
Recently, it was proposed to combine PSO with other global optimization algorithms such as GA, Evolutionary programming (EP) or simulated annealing (SA) together, in order to address this issue (Eberhart \& Shi 2001; Esmin et al 2005; Gaing 2003; Gaing 2004; Hong \& $\mathrm{Hu} 2005)$. The basic idea is to increase the information exchange among particles using the crossover operator and therefore, escape the local minima by mutation. These ideas are also applied to power system optimization problems (Hu et al 2004; Naka et al 2003; Niknam \& Amiri 2010; Niknam et al 2010; Niknam 2009b; Olamaei et al 2008). In these approaches, new generation members are produced using evolutionary algorithms in each iteration. Then PSO movement rule is applied to these new members and provide better opportunity of exploring new places.

In this paper, a new method is proposed to incorporate intelligent decision-making structure of ant colony optimization algorithm into the FAPSO algorithm, where the global best position is unique for every particle. However, it uses random selection procedure of ACO algorithm to assign different global best positions to every distinct agent. This new algorithm is called HFAPSO and is applied to solve the proposed DFR. The control variables are status of the tie and sectionalizing switches.

To solve the DFR problem using the HFAPSO algorithm, the following steps supposed to be taken and repeated.

\section{Step 1: Defining the input data}

Input data includes network configuration, line impedance, and status of switches are defined.

\section{Step 2: Transforming the constrained DFR to the unconstrained DFR}

The proposed DFR problem needs to be transformed into an unconstrained one by constructing an augmented objective function incorporating penalty factors for any value violating the constraints:

$$
F(X)=J(X)+k_{1}\left(\sum_{j=1}^{N_{e q}}\left(h_{j}(X)^{2}\right)+k_{2}\left(\sum_{j=1}^{N u e q}\left(\operatorname{Max}\left[0,-g_{j}(X)\right]\right)^{2}\right)\right) .
$$

$J(X)$ is the objective function value of the DFR problem. $N_{e q}$ and $N_{u e q}$ are the number of equality and inequality constraints of the DFR problem, respectively. $h_{i}(X)$ and $g_{i}(X)$ are the equality and inequality constraints, respectively. $k_{1}$ and $k_{2}$ are penalty factors.

\section{Step 3: Generating the initial population and velocity}

The initial population and initial velocity for each particle are randomly generated as follows:

$$
\begin{aligned}
\text { Population } & =\left[\begin{array}{c}
X_{1} \\
X_{2} \\
\ldots \\
X_{N}
\end{array}\right] \\
X_{i} & =\left[x_{i}\right]_{1 \times n}=\left[\mathrm{Tie}_{1}, \mathrm{Tie}_{2}, \ldots, \mathrm{Tie}_{N_{\text {tie }}}, S w_{1}, S w_{2}, \ldots, S w_{N_{\text {tie }}}\right], \\
i & =1,2,3, \ldots, N \\
n & =2 \times N_{\text {tie }}
\end{aligned}
$$




$$
\begin{aligned}
\text { Velocity } & =\left[\begin{array}{c}
V_{1} \\
V_{2} \\
\ldots \\
V_{N}
\end{array}\right] \\
V_{i} & =\left[v_{i}\right]_{1 \times n}=\left[\mathrm{Tie}_{1}, \mathrm{Tie}_{2}, \ldots, \mathrm{Tie}_{N_{\text {tie }}}, S w_{1}, S w_{2}, \ldots, S w_{N_{\text {tie }}}\right], \\
i & =1,2,3, \ldots, N \\
n & =2 \times N_{\text {tie }},
\end{aligned}
$$

where $x_{j}$ is the $j^{\text {th }}$ control variable. $V_{i}$ and $X_{i}$ are position and velocity of the $i^{\text {th }}$ individual, respectively. $n$ is the number of control variables. $N$ is the number of swarms. In the above equations, $\mathrm{Tie}_{i}$ is randomly generated and its value is 0 or 1 . It should be noted that the value of $S w_{i}$ is randomly generated so that the distribution system remains radial. On the other hand, when the value of $\mathrm{Tie}_{i}$ is equal to zero, the value of $S w_{i}$ is equal to zero, too. And, when the value of $\mathrm{Tie}_{i}$ is equal to 1 , that of the sectionalizing switch, which forms a loop with $\mathrm{Tie}_{i}$ is randomly selected.

\section{Step 4: Generating the initial trail intensity}

At first, it is assumed that trail intensity between each pair of swarms is the same and generated as follows:

$$
\begin{aligned}
\text { Trail_Intensity } & =\left[\tau_{i j}\right]_{N \times N} \\
\tau_{i j} & =\tau_{0},
\end{aligned}
$$

where $\tau_{i j}$ and $\tau_{0}$ are trial intensity between $i^{\text {th }}$ and $j^{\text {th }}$ swarms and initial trial intensity, respectively.

Step 5: Calculating the augmented objective function value

The augmented objective function (equation (15)) is evaluated for each individual using the result of the distribution load flow.

Step 6: Sorting the initial population based on the objective function values

The initial population is sorted in descending order based on the value of the objective function.

Step 7: Selecting the best global position

The individual that has the maximum objective function, is selected as the best global position (Gbest).

Step 8: Selecting the best local position

The best local position (Pbest) is selected for each individual.

Step 9: Selecting the $i^{\text {th }}$ individual

The $i^{\text {th }}$ individual is selected and neighbours of this particle should be defined dynamically as:

$$
S_{i}=\left\{X_{j} \mid\left\|X_{i}-X_{j}\right\| \leq 2 D_{0}\left(\frac{1}{1-\exp \left(\frac{-a t}{t_{\max }}\right)}\right), i \neq j\right\},
$$

where $D_{0}$ is the initial neighbourhood radius, $a$ is a parameter used, to tune the neighborhood radius over the iteration, $t$, and $\|\ldots\|$ denotes the Euclidean distance operator. 
Step 10: Updating the FAPSO parameters as described in the previous section

\section{Step 11: Calculating the next position for the $i^{\text {th }}$ individual}

There are two approaches to calculate the next position:

- Case A) if $S_{i} \neq\{\}$, where \{\} denotes the null set.

In this case, at first, the transition probabilities between the $X_{i}$ and each individual in $S_{i}$ are calculated as indicated (19):

$$
\begin{aligned}
{[\text { Probability }]_{i} } & =\left[P_{i 1}, P_{i 2}, \ldots, P_{i, M}\right]_{1 \times M} \\
P_{i j} & =\frac{\left(\tau_{i j}\right)^{\gamma_{2}}\left(1 / L_{i j}\right)^{\gamma_{1}}}{\sum_{j=1}^{M}\left(\tau_{i j}\right)^{\gamma_{2}}\left(1 / L_{i j}\right)^{\gamma_{1}}} \\
L_{i j} & =\frac{1}{\left|F\left(X_{i}\right)-F\left(X_{j}\right)\right|},
\end{aligned}
$$

where $P_{i j}$ is the state transition probability between $X_{i}$ and $j^{\text {th }}$ individual in $S_{i}$ and $M$ is the number of members in $S_{i}$.

Then the cumulative probabilities are calculated as:

$$
\begin{aligned}
& \text { [Cumulative probability }]_{i}=\left[C_{1}, C_{2}, \ldots, C_{M}\right]_{1 \times M}, \\
& \text { where } C_{1}=P_{i 1} \\
& C_{2}=C_{1}+P_{i 2} \\
& \cdots \\
& C_{j}=C_{j-1}+P_{i j} \\
& \cdots \\
& C_{M}=C_{M-1}+P_{i M} .
\end{aligned}
$$

In the above equations, $C_{j}$ is cumulative probability for the $j^{\text {th }}$ individual in $S_{i}$. The roulette wheel is used for random selection of the best global position as follows.

A number between 0 and 1 is randomly generated and compared with the calculated cumulative probabilities. The first term of the cumulative probabilities $\left(C_{j}\right)$, which is greater than the generated number, is selected and the associated position is considered as the best global position.

The $i^{\text {th }}$ particle is then moved according to the following rules and the parameters evaluated in step 10 , if $X_{j}$ is selected as the best:

$$
\left\{\begin{array}{l}
V_{i}^{(t+1)}=\omega \cdot V_{i}^{(t)}+c_{1} \cdot \operatorname{rand}_{1}(\mathrm{\circ}) \cdot\left(\text { Pbest }_{i}-X_{i}^{(t)}\right)+c_{2} \cdot \operatorname{rand}_{2}(\mathrm{\circ}) \cdot\left(X_{j}-X_{i}^{(t)}\right) \\
X_{i}^{(t+1)}=X_{i}^{(t)}+V_{i}^{(t+1)} .
\end{array}\right.
$$

The presumed pheromone level between $X_{i}$ and $X_{j}$ is updated at the next stage:

$$
\tau_{i j}(t+1)=\rho \cdot \tau_{i j}(t)+P_{i j} .
$$

- Case B) if $S_{i}=\{\}$, which means that there is no individual in the neighbourhood of the particle. 
In this case, the $i^{\text {th }}$ particle is moved according to the following rules and the parameters evaluated in step 10:

$$
\left\{\begin{array}{l}
V_{i}^{(t+1)}=\omega \cdot V_{i}^{(t)}+c_{1} \cdot \operatorname{rand}_{1}(\circ) \cdot\left(\text { Pbest }_{i}-X_{i}^{(t)}\right)+c_{2} \cdot \operatorname{rand}_{2}(\mathrm{\circ}) \cdot\left(\text { Gbest }-X_{i}^{(t)}\right) \\
X_{i}^{(t+1)}=X_{i}^{(t)}+V_{i}^{(t+1)}
\end{array}\right.
$$

Then, the trail intensity is updated as:

$$
\tau_{i j}(t+1)=\rho \cdot \tau_{i j}(t)+r ; 0 \cdot 1 \leq r \leq 0 \cdot 5,
$$

where index $j$ represents the best particle index in the group.

The modified position for the $i^{\text {th }}$ individual is checked with its limit.

Step 12: If all individuals are selected, go to the next step, otherwise $i=i+1$ and go back to step 6.

\section{Step 13: Checking the termination criteria.}

If the current iteration number reaches the predetermined maximum iteration number, the search procedure is stopped, otherwise the initial population is replaced with the new population of swarms and then goes back to step 5 .

The last Gbest is the solution of the problem.

\section{Simulation and results}

In this section, the HFAPSO algorithm is employed to solve the DFR for two distribution test feeders. The parameters required for implementation of the HFAPSO algorithm are $\gamma_{1}, \gamma_{2}, \rho, a, r$ and $D_{0}$. The optimal values for these parameters are $\gamma_{1}=\gamma_{2}=1 \cdot 0, \rho=.99$, $a=15, r=0 \cdot 5, D_{0}=10$, which are determined by 100 runs of the algorithm. The number of swarms is 24 .

\subsection{Case 1-Baran \& Wu test system}

The Baran \& Wu (1989) distribution test system is a hypothetical $12.66 \mathrm{kV}$ system and has two feeders, 32 buses, and 5 looping branches. In this system, there are five tie switches and

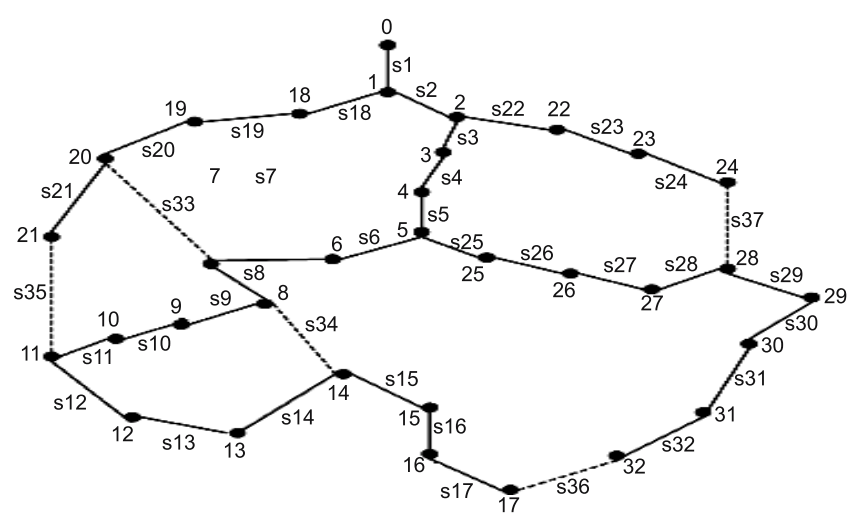

Figure 5. A single line diagram of Baran \& Wu distribution test system. 
Table 4. Results obtained by different methods for initial configuration.

\begin{tabular}{|c|c|c|c|c|c|}
\hline Method & $\begin{array}{c}\text { Power } \\
\text { losses }[\mathrm{kW}]\end{array}$ & $\begin{array}{l}\text { Minimum } \\
\text { voltage [p.u] }\end{array}$ & $\begin{array}{c}\text { Loss } \\
\text { reduction [\%] }\end{array}$ & $\begin{array}{c}\mathrm{CPU} \\
\text { time }[\mathrm{sec}]\end{array}$ & $\begin{array}{c}\text { Open } \\
\text { switches }\end{array}$ \\
\hline $\begin{array}{l}\text { Optimum } \\
\text { (Vanderson } \\
\text { et al 2005)] }\end{array}$ & $139 \cdot 53$ & 0.938 & $31 \cdot 14$ & $647 \cdot 03$ & s7, s9, s14, s32, s37 \\
\hline $\begin{array}{l}\text { The proposed } \\
\text { algorithm }\end{array}$ & $139 \cdot 53$ & 0.938 & $31 \cdot 14$ & 8 & s7, s9, s14, s32, s37 \\
\hline $\begin{array}{l}\text { Goswami \& } \\
\text { Basu (1992) }\end{array}$ & $139 \cdot 53$ & 0.938 & $31 \cdot 14$ & $0 \cdot 87$ & s7, s9, s14, s32, s37 \\
\hline $\begin{array}{l}\text { McDermott } \\
\text { et al (1999) }\end{array}$ & 139.53 & 0.938 & $31 \cdot 14$ & 1.99 & s7, s9, s14, s32, s37 \\
\hline $\begin{array}{l}\text { Shirmohammadi \& } \\
\text { Hong (1989) }\end{array}$ & $140 \cdot 26$ & 0.9378 & $30 \cdot 78$ & $0 \cdot 14$ & $\mathrm{~s} 7, \mathrm{~s} 10, \mathrm{~s} 14, \mathrm{~s} 32, \mathrm{~s} 37$ \\
\hline $\begin{array}{l}\text { Vanderson et al } \\
\text { (2005) }\end{array}$ & $139 \cdot 53$ & 0.938 & $31 \cdot 14$ & 1.66 & s7, s9, s14, s32, s37 \\
\hline
\end{tabular}

thirty two sectionalizing switches. The system data has been given in (McDermott et al 1999) and the single line diagram of this system has been shown in figure 5 . The real and reactive loads are $5058.25 \mathrm{~kW}$ and $2547.32 \mathrm{kVar}$. The normal open switches, s33, s34, s35, s36 and s37, are illustrated by doted lines. The normally closed switches, s1 to s32, are shown by solid lines. When all tie switches are open, the losses and minimum per unit voltage are $202.67 \mathrm{~kW}$ and 0.913 , respectively.

Performances of the represented algorithm and some other algorithms are compared in table 4 . The results illustrate that the proposed algorithm leads to the global optimum configuration.

A comparison between the proposed HFAPSO, HPSO (Li et al 2008), ACO (Niknam 2009a; Niknam 2009b; Niknam 2009c), the original PSO (Niknam et al 2009a; Niknam 2009c), hybrid PSO (Niknam 2009a; Niknam 2009b; Niknam 2009c), and GA (Niknam 2009a; Niknam 2009b; Niknam 2009c) is shown in tables 5 and 6 for 100 random trials.

In tables 5 and 6 , the smallest and the largest values of the minimized objective function are referred to as the 'Best solution' and the 'Worst solution', respectively. Comparisons of the best and worst solutions of the proposed optimization algorithm with those of the other methods confirm the effectiveness of the proposed method. In addition to the best and worst

Table 5. Comparison of average and standard deviation for initial configuration.

\begin{tabular}{lcccccc}
\hline Method & $\begin{array}{c}\text { Average of } \\
\text { objective } \\
\text { function value }\end{array}$ & $\begin{array}{c}\text { Standard } \\
\text { deviation }\end{array}$ & $\begin{array}{c}\text { Worst } \\
\text { solution }\end{array}$ & $\begin{array}{c}\text { Best } \\
\text { solution }\end{array}$ & $\begin{array}{c}\text { CPU } \\
\text { time [sec] }\end{array}$ & $\begin{array}{c}\text { No of global } \\
\text { solution }\end{array}$ \\
\hline HFAPSO & $99648 \cdot 081$ & 0 & $99648 \cdot 081$ & 99648.081 & $\sim 7$ & 100 \\
HPSO & 99335.42 & 361.7975 & 98920.952 & 99648.081 & $\sim 9$ & 80 \\
GA & $98165 \cdot 13$ & 1541.396 & $95694 \cdot 146$ & 99648.081 & $\sim 20$ & 50 \\
ACO & 98469.26 & 1194.888 & 96443.691 & 99648.081 & $\sim 12$ & 65 \\
PSO & $98006 \cdot 81$ & $1717 \cdot 162$ & 95694.146 & 99648.081 & $\sim 10$ & 40 \\
Hybrid PSO & $99640 \cdot 351$ & 8.6237 & 99636.476 & 99648.081 & $\sim 7$ & 89 \\
\hline
\end{tabular}


Table 6. Simulation results based on power losses and minimum voltage value for initial configuration.

\begin{tabular}{|c|c|c|c|c|c|c|}
\hline \multirow[b]{2}{*}{ Method } & \multicolumn{3}{|c|}{ Best solution } & \multicolumn{3}{|c|}{ Worst solution } \\
\hline & $\begin{array}{c}\text { Power } \\
\text { losses }[\mathrm{kW}]\end{array}$ & $\begin{array}{c}\text { Minimum } \\
\text { voltage [p.u] }\end{array}$ & $\begin{array}{c}\text { Open } \\
\text { switches }\end{array}$ & $\begin{array}{c}\text { Power } \\
\text { losses }[\mathrm{kW}]\end{array}$ & $\begin{array}{l}\text { Minimum } \\
\text { voltage [p.u] }\end{array}$ & $\begin{array}{c}\text { Open } \\
\text { switches }\end{array}$ \\
\hline HFAPSO & 139.53 & 0.938 & $\begin{array}{l}\text { s7, s9, s14, } \\
\text { s32, s37 }\end{array}$ & 139.53 & 0.938 & $\begin{array}{l}\text { s7, s9, s14, } \\
\text { s32, s37 }\end{array}$ \\
\hline HPSO & $139 \cdot 53$ & $0 \cdot 938$ & $\begin{array}{l}\text { s7, s9, s14, } \\
\text { s32, s37 }\end{array}$ & $142 \cdot 73917$ & 0.9378 & $\begin{array}{c}\mathrm{s} 7, \mathrm{~s} 11, \mathrm{~s} 32 \\
\mathrm{~s} 34, \mathrm{~s} 37\end{array}$ \\
\hline GA & $139 \cdot 53$ & 0.938 & $\begin{array}{l}\text { s7, s9, s14, } \\
\text { s32, s37 }\end{array}$ & $151 \cdot 12388$ & 0.933 & $\begin{array}{c}\text { s9, s32, s33, } \\
\text { s34, s37 }\end{array}$ \\
\hline ACO & $139 \cdot 53$ & 0.938 & $\begin{array}{l}\text { s7, s9, s14, } \\
\text { s32, s37 }\end{array}$ & $144 \cdot 39$ & 0.936 & $\begin{array}{c}\text { s6, s11, s32, } \\
\text { s34, s37 }\end{array}$ \\
\hline PSO & $139 \cdot 53$ & $0 \cdot 938$ & $\begin{array}{l}\text { s7, s9, s14, } \\
\text { s32, s37 }\end{array}$ & $151 \cdot 12388$ & 0.933 & $\begin{array}{c}\text { s9, s32, s33, } \\
\text { s34, s37 }\end{array}$ \\
\hline Hybrid PSO & $139 \cdot 53$ & $0 \cdot 938$ & $\begin{array}{l}\text { s7, s9, s14, } \\
\text { s32, s37 }\end{array}$ & $142 \cdot 73917$ & 0.9378 & $\begin{array}{c}\text { s7, s11, s32, } \\
\text { s32, s37 }\end{array}$ \\
\hline
\end{tabular}

solutions, table 5 provides the standard deviation and average value of the objective function (minimized), based on the proposed method and the others. It can be noticed from table 5 that the foregoing variables assume considerably smaller values under the proposed algorithm than the other methods.

Figure 6 illustrates the convergence characteristics of the HFAPSO, HPSO, PSO, ACO, and GA for the best solutions.

It can be seen from figure 5 that the value of the objective function settles at the minimum after 14 iterations, and does not vary thereafter.

In order to show that the proposed algorithm does not depend on the initial switching configuration, the initial configuration was changed by closing the normally open switches s33 and s37 and opening the normally closed s3 and s6. For this case, the initial losses and minimum voltage in per unit are $208 \cdot 15 \mathrm{~kW}$ and 0.9212 , respectively.

Table 7 illustrates the simulation results in this case. The results show that again the proposed algorithm gives the global optimum configuration, which confirms that the proposed approach does not depend on the initial switching configuration.

A comparison between the HFAPSO, HPSO (Li et al 2008), ACO (Niknam 2009a; Niknam 2009b; Niknam 2009c), the original PSO (Niknam et al 2009a; Niknam 2009c), hybrid PSO (Niknam 2009a; Niknam 2009b; Niknam 2009c), and GA (Niknam 2009a; Niknam 2009b; Niknam 2009c) for 100 random trials is shown in tables 8 and 9.

The simulation results of tables 4 to 9 , and figure 5 show that the computation time of the proposed method is significantly less than that of GA, PSO, and ACO. Therefore, it can be implemented without any restriction in practical networks. This method not only provides a better solution compared to other methods, but also has zero standard deviation for different trials.

\subsection{Case 2-A 70-Bus $11 \mathrm{kV}$ radial distribution system}

A single line diagram of the $11 \mathrm{kV}$ radial distribution system having two substations, four feeders, 70 nodes, and 78 branches (including tie branches) is shown in figure 7 . The system data is given in Debaprya (2006). 

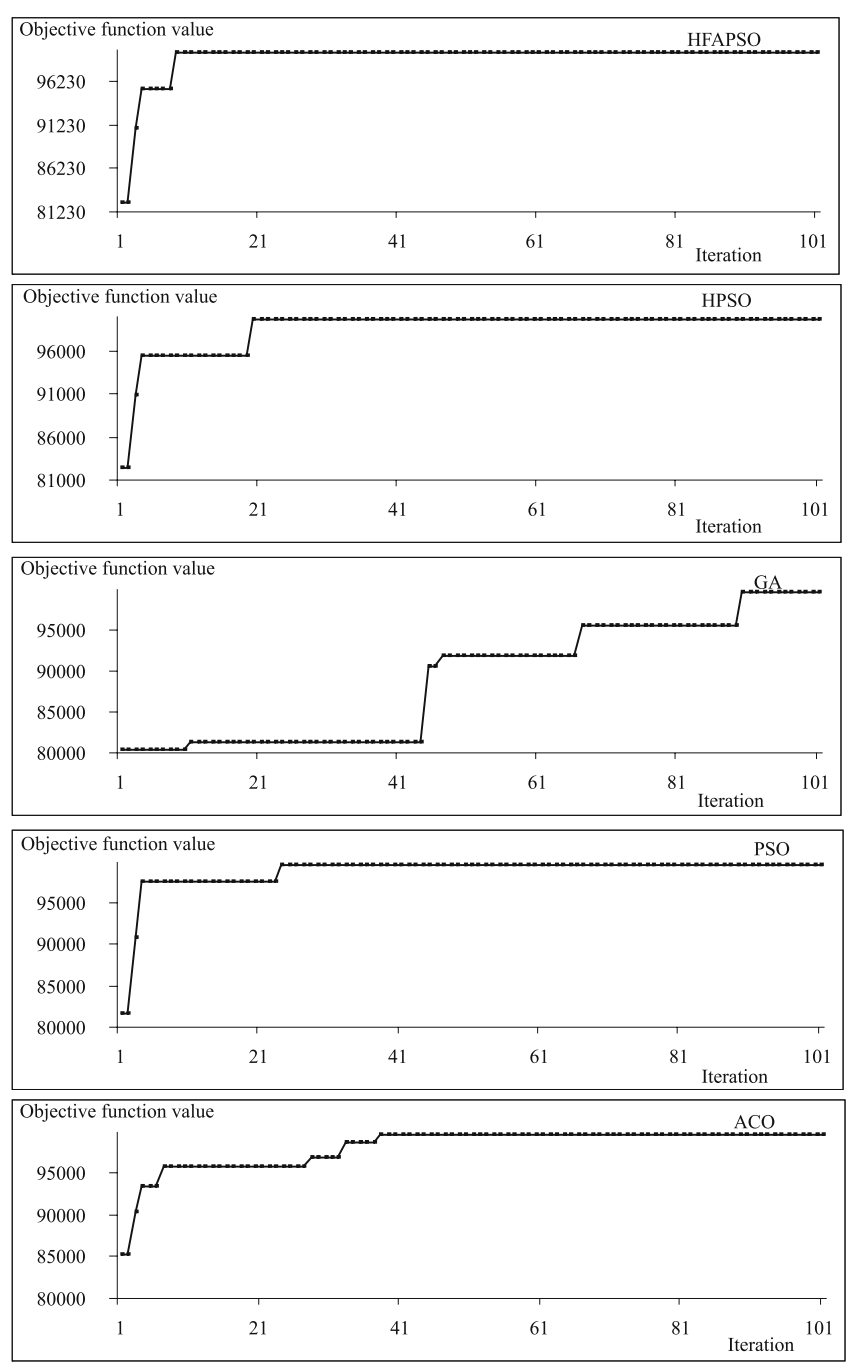

Figure 6. Convergence characteristics of the HFAPSO, HPSO, PSO, ACO and GA for the best solutions.

For the initial configuration, power losses and the minimum voltage in per unit are $227.53 \mathrm{~kW}$ and 0.9052 , respectively. The simulation results are presented in table 10 . As shown in the table, only 6 switches have changed out of 11 . The currents of the feeders are also more balanced after reconfiguration.

Tables 11 and 12 show the currents of the feeders before and after reconfiguration. It is seen that the current of each feeder is more balanced after reconfiguration.

A comparison between the HFAPSO, HPSO (Li et al 2008), ACO (Niknam 2009a; Niknam 2009b; Niknam 2009c), the original PSO (Niknam et al 2009a; Niknam 2009c), hybrid PSO (Niknam 2009a; Niknam 2009b; Niknam 2009c), and GA (Niknam 2009a; Niknam 2009b; Niknam 2009c) for 100 random trials is shown in tables 12 and 13.

The results of tables 12 and 13 indicate that the HFAPSO algorithm is very precise. In other words, not only does this method reach a much better optimal solution in comparison with the others, but also its standard deviation for different trials is zero. 
Table 7. Results for different methods.

\begin{tabular}{|c|c|c|c|c|c|}
\hline Method & $\begin{array}{c}\text { Power } \\
\text { losses }[\mathrm{kW}]\end{array}$ & $\begin{array}{c}\text { Minimum } \\
\text { voltage }[\mathrm{p} . \mathrm{u}]\end{array}$ & $\begin{array}{c}\text { Loss } \\
\text { reduction }[\%]\end{array}$ & $\begin{array}{c}\mathrm{CPU} \\
\text { time }[\mathrm{sec}]\end{array}$ & $\begin{array}{c}\text { Open } \\
\text { switches }\end{array}$ \\
\hline $\begin{array}{l}\text { Optimum } \\
\text { (Vanderson } \\
\text { et al 2005) }\end{array}$ & $139 \cdot 53$ & 0.938 & $31 \cdot 14$ & $647 \cdot 03$ & s7, s9, s14, s32, s37 \\
\hline $\begin{array}{l}\text { The proposed } \\
\text { algorithm }\end{array}$ & 139.53 & 0.938 & $31 \cdot 14$ & 8 & s7, s9, s14, s32, s37 \\
\hline $\begin{array}{l}\text { Goswami \& } \\
\text { Basu (1992) }\end{array}$ & $143 \cdot 69$ & 0.9397 & $29 \cdot 08$ & 0.65 & s7, s9, s14, s32, s37 \\
\hline $\begin{array}{l}\text { MeDemott } \\
\text { et al }(1999)\end{array}$ & $139 \cdot 53$ & $0 \cdot 938$ & $31 \cdot 14$ & $1 \cdot 99$ & s7, s9, s14, s32, s37 \\
\hline $\begin{array}{l}\text { Shirmohammadi \& } \\
\text { Hong (1989) }\end{array}$ & $140 \cdot 26$ & 0.9378 & $30 \cdot 78$ & $0 \cdot 14$ & s7, s10, s14, s32, s37 \\
\hline $\begin{array}{l}\text { Vanderson etal } \\
(2005)\end{array}$ & $139 \cdot 53$ & $0 \cdot 938$ & $31 \cdot 14$ & $1 \cdot 66$ & s7, s9, s14, s32, s37 \\
\hline
\end{tabular}

Table 8. Comparison of average and standard deviation for 100 trials.

\begin{tabular}{|c|c|c|c|c|c|c|}
\hline Method & $\begin{array}{c}\text { Average of } \\
\text { objective } \\
\text { function value }\end{array}$ & $\begin{array}{l}\text { Standard } \\
\text { deviation }\end{array}$ & $\begin{array}{c}\text { Worst } \\
\text { solution }\end{array}$ & $\begin{array}{c}\text { Best } \\
\text { solution }\end{array}$ & $\begin{array}{c}\text { CPU } \\
\text { time }[\mathrm{sec}]\end{array}$ & $\begin{array}{l}\text { Number of } \\
\text { global solution }\end{array}$ \\
\hline HFAPSO & $99648 \cdot 0810$ & 0 & $99648 \cdot 081$ & $99648 \cdot 081$ & $\sim 7$ & 100 \\
\hline HPSO & 99381.467 & $356 \cdot 38$ & $98920 \cdot 952$ & $99648 \cdot 081$ & $\sim 9$ & 85 \\
\hline GA & $98798 \cdot 229$ & $1367 \cdot 602$ & $95694 \cdot 146$ & $99648 \cdot 081$ & $\sim 20$ & 52 \\
\hline $\mathrm{ACO}$ & $98902 \cdot 3115$ & $1175 \cdot 271964$ & 96443.691 & $99648 \cdot 081$ & $\sim 12$ & 67 \\
\hline PSO & 98284.6551 & $1912 \cdot 61832$ & $95694 \cdot 146$ & $99648 \cdot 081$ & $\sim 10$ & 39 \\
\hline \multicolumn{7}{|l|}{ Hybrid } \\
\hline PSO[46] & 99641.483 & $9 \cdot 6781$ & 99634.923 & $99648 \cdot 081$ & $\sim 7$ & 89 \\
\hline
\end{tabular}

Table 9. Simulation results based on power losses and minimum voltage value for 100 trials.

\begin{tabular}{|c|c|c|c|c|c|c|}
\hline \multirow[b]{2}{*}{ Method } & \multicolumn{3}{|c|}{ Best solution } & \multicolumn{3}{|c|}{ Worst solution } \\
\hline & $\begin{array}{c}\text { Power } \\
\text { losses }[\mathrm{kW}]\end{array}$ & $\begin{array}{c}\text { Minimum } \\
\text { voltage [p.u] }\end{array}$ & $\begin{array}{c}\text { Open } \\
\text { switches }\end{array}$ & $\begin{array}{c}\text { Power } \\
\text { losses }[\mathrm{kW}]\end{array}$ & $\begin{array}{c}\text { Minimum } \\
\text { Voltage [p.u] }\end{array}$ & $\begin{array}{c}\text { Open } \\
\text { switches }\end{array}$ \\
\hline HFAPSO & $139 \cdot 53$ & 0.938 & $\begin{array}{c}\text { s7, s9, s14, } \\
\text { s32, s37 }\end{array}$ & $139 \cdot 53$ & 0.938 & $\begin{array}{c}\text { s7, s9, s14, } \\
\text { s32, s37 }\end{array}$ \\
\hline HPSO & $139 \cdot 53$ & 0.938 & $\begin{array}{c}\text { s7, s9, s14, } \\
\text { s32, s37 }\end{array}$ & $142 \cdot 73917$ & 0.9378 & $\begin{array}{c}\text { s7, s11, s32, } \\
\text { s34, s37 }\end{array}$ \\
\hline GA & $139 \cdot 53$ & 0.938 & $\begin{array}{c}\text { s7, s9, s14, } \\
\text { s32, s37 }\end{array}$ & $151 \cdot 12388$ & 0.933 & $\begin{array}{c}\text { s9, s32, s33, } \\
\text { s34, s37 }\end{array}$ \\
\hline $\mathrm{ACO}$ & $139 \cdot 53$ & 0.938 & $\begin{array}{c}\text { s7, s9, s14, } \\
\text { s32, s37 }\end{array}$ & $144 \cdot 39$ & 0.936 & $\begin{array}{c}\text { s6, s11, s32, } \\
\text { s34, s37 }\end{array}$ \\
\hline PSO & $139 \cdot 53$ & 0.938 & $\begin{array}{c}\text { s7, s9, s14, } \\
\text { s32, s37 }\end{array}$ & $151 \cdot 12388$ & 0.933 & $\begin{array}{c}\text { s9, s32, s33, } \\
\text { s34, s37 }\end{array}$ \\
\hline Hybrid PSO & $139 \cdot 53$ & 0.938 & $\begin{array}{c}\text { s7, s9, s14, } \\
\text { s32, s37 }\end{array}$ & $142 \cdot 73917$ & 0.9378 & $\begin{array}{c}\text { s7, s11, s32, } \\
\text { s34, s37 }\end{array}$ \\
\hline
\end{tabular}




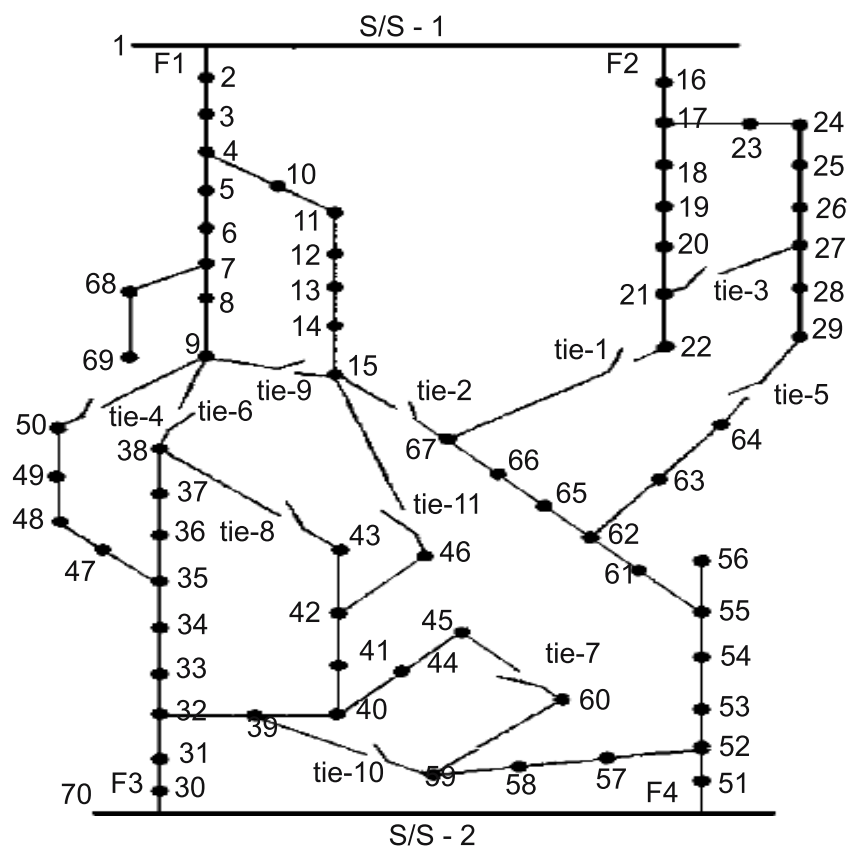

Figure 7. Single line diagram of a $11 \mathrm{kV}$ distribution test system.

Figure 8 shows the convergence characteristics of HFAPSO, HPSO, PSO, ACO, and GA for the best solutions.

The results of the convergence time suggest that the HFAPSO algorithm is the best compared to the others in terms of the required number of iterations.

Table 10. Results for different methods for case 2.

\begin{tabular}{lcccccc}
\hline Method & $\begin{array}{c}\text { Power } \\
\text { losses } \\
{[\mathrm{kW}]}\end{array}$ & $\begin{array}{c}\text { Minimum } \\
\text { voltage } \\
{[\mathrm{p} . \mathrm{u}]}\end{array}$ & $\begin{array}{c}\text { Loss } \\
\text { reduction } \\
{[\%]}\end{array}$ & $\begin{array}{c}\text { CPU } \\
\text { time } \\
{[\mathrm{sec}]}\end{array}$ & $\begin{array}{c}\text { Open sectionalizing } \\
\text { switches }\end{array}$ & $\begin{array}{c}\text { Closed tie } \\
\text { switches }\end{array}$ \\
\hline $\begin{array}{l}\text { The proposed } \\
\text { algorithm }\end{array}$ & $205 \cdot 32$ & 0.9268 & 9.76 & 5 & $\begin{array}{c}\text { s26-27, s14-15, s37-38, } \\
\text { s49-50, s44-45, s65-66 }\end{array}$ & $\begin{array}{c}\text { tie } 7, \text { tie } 3, \text { tie } 4, \\
\text { tie } 9\end{array}$ \\
$\begin{array}{l}\text { Debaprya } \\
\text { (2006) }\end{array}$ & $205 \cdot 32$ & 0.9268 & 9.76 & 3 & $\begin{array}{c}\text { s26-27, s14-15, s37-38, } \\
\text { tie 1, tie 3, tie 4, }\end{array}$ \\
\hline
\end{tabular}

Table 11. Feeder current before and after reconfiguration.

\begin{tabular}{lccc}
\hline Feeder number & Before reconfiguration [A] & After reconfiguration [A] & Capacity of feeder [A] \\
\hline IF1 & 99.9 & 117.01 & 270 \\
IF2 & 109.01 & 131.57 & 270 \\
IF3 & 162.3 & 133.93 & 270 \\
IF4 & 148.86 & 135.13 & 270 \\
\hline
\end{tabular}


Table 12. Comparison of average and standard deviation for 100 trials.

\begin{tabular}{lcccccc}
\hline Method & $\begin{array}{c}\text { Average of } \\
\text { objective } \\
\text { function value }\end{array}$ & $\begin{array}{c}\text { Standard } \\
\text { deviation }\end{array}$ & $\begin{array}{c}\text { Worst } \\
\text { solution }\end{array}$ & $\begin{array}{c}\text { Best } \\
\text { solution }\end{array}$ & $\begin{array}{c}\text { CPU } \\
\text { time [sec] }\end{array}$ & $\begin{array}{c}\text { No. of global } \\
\text { solution }\end{array}$ \\
\hline HFAPSO & $149472 \cdot 1$ & 0 & $149472 \cdot 1$ & $149472 \cdot 1$ & $\sim 11$ & 100 \\
HPSO & $149210 \cdot 4$ & $468 \cdot 1635$ & $148390 \cdot 8$ & $149472 \cdot 1$ & $\sim 12$ & 80 \\
GA & 147247.7 & $2312 \cdot 094$ & $143582 \cdot 09$ & $149472 \cdot 1$ & $\sim 30$ & 55 \\
ACO & $147773 \cdot 3$ & $2178 \cdot 864$ & $144630 \cdot 5$ & $149472 \cdot 1$ & $\sim 18$ & 68 \\
PSO & $145676 \cdot 3$ & $2861 \cdot 175$ & 143520.9 & $149472 \cdot 1$ & $\sim 15$ & 41 \\
Hybrid PSO & $149453 \cdot 4$ & 21.584 & $149432 \cdot 82$ & $149472 \cdot 1$ & $\sim 12$ & 90 \\
\hline
\end{tabular}

The simulation results show that the HFAPSO method has a short run time and zero standard deviation for different trials.

\section{Conclusion}

The distribution feeder reconfiguration problem has a vector-valued objective function with different elements. This paper proposed an efficient hybrid evolutionary algorithm, called HFAPSO, to solve this multi-objective optimization problem. PSO is one of the most powerful optimization algorithms. However, the performance of the algorithm depends on its parameters. In this paper, a fuzzy system has been used to adjust the parameters. Also in the PSO algorithm, if the best solution does not change for the number of generation, the algorithm converges to a local solution. To overcome this drawback in PSO algorithm, this article has proposed a hybrid algorithm based on a combination of two powerful optimization algorithms; Ant Colony Optimization and fuzzy adaptive Particle Swarm Optimization. In terms of the novel algorithm, the decision-making process of each particle for selecting the best direction before its movement is reinforced by the ACO method. This hybrid method can provide a good opportunity for all individuals and especially the most-fit particle to search the surrounding area better. The efficiency of HFAPSO was validated by extensive computer experiments. In the simulations, global optimum solutions for the system losses, the voltage

Table 13. Simulation results based on power losses and minimum voltage value for 100 trials for case 2 .

\begin{tabular}{lccccc}
\hline & \multicolumn{2}{c}{ Best solution } & & \multicolumn{2}{c}{ Worst solution } \\
\cline { 2 - 3 } \cline { 5 - 6 } Method & $\begin{array}{c}\text { Power } \\
\text { losses [kW] }\end{array}$ & $\begin{array}{c}\text { Minimum } \\
\text { voltage [p.u] }\end{array}$ & & $\begin{array}{c}\text { Power } \\
\text { losses [kW] }\end{array}$ & $\begin{array}{c}\text { Minimum } \\
\text { voltage [p.u] }\end{array}$ \\
\hline HFAPSO & 205.32 & 0.9268 & & 205.32 & 0.9268 \\
HPSO & 205.32 & 0.9268 & & 207.583 & 0.921 \\
GA & 205.32 & 0.9268 & & 212.01 & 0.915 \\
ACO & 205.32 & 0.9268 & & 210.532 & 0.918 \\
PSO & 205.32 & 0.9268 & & 212.34 & 0.914 \\
Hybrid PSO[46] & 205.32 & 0.9268 & & 207.583 & 0.921 \\
\hline
\end{tabular}



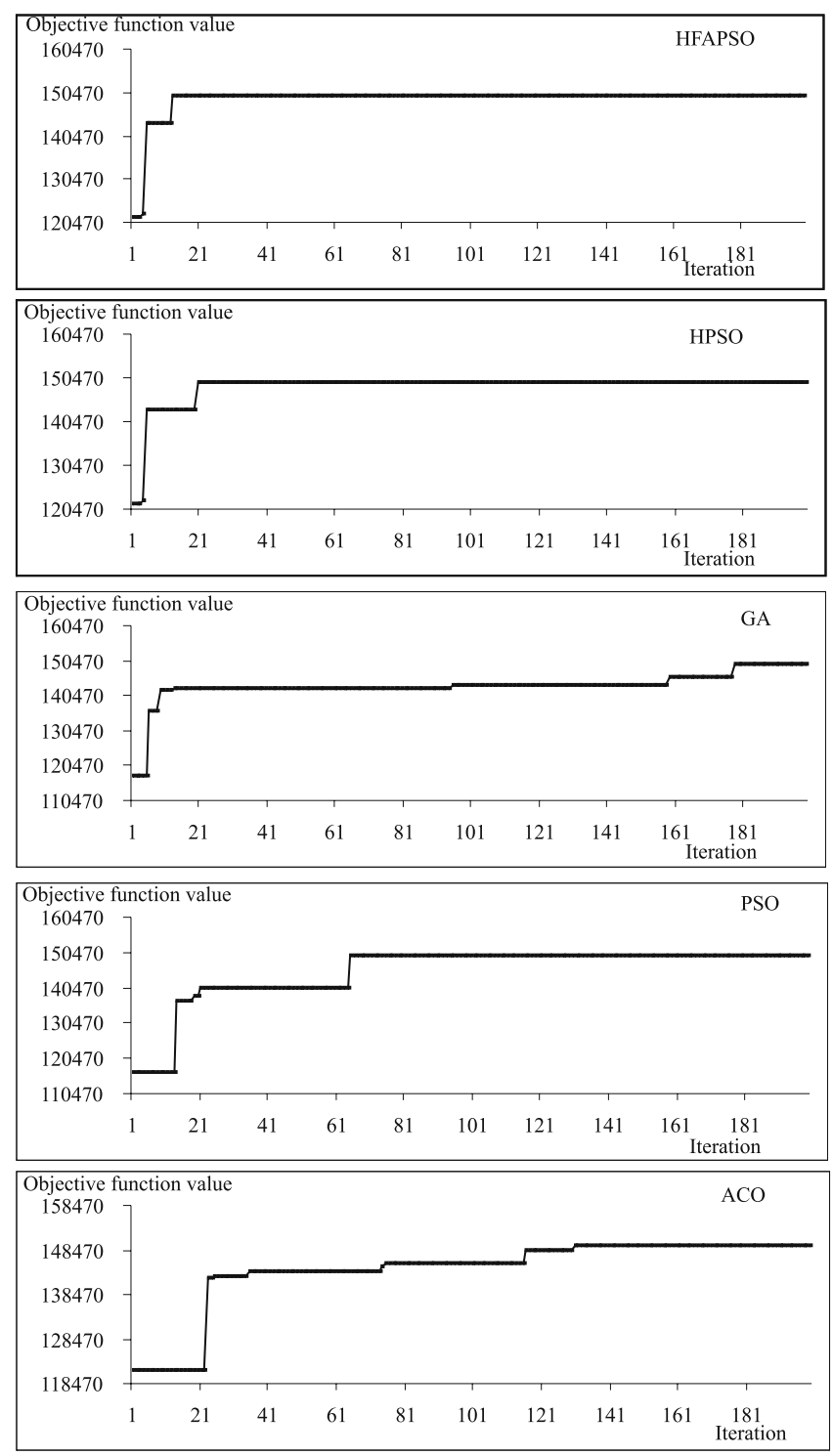

Figure 8. Convergence characteristics of the HFAPSO, HPSO, PSO, ACO and GA for the best solutions.

deviation, and load balancing were being computed while the number of switching operations was minimized. Compared to other evolutionary methods, HFAPSO achieves much better solutions and zero standard deviation for different trials. On the other hand, it does not depend on the initial status of network switches as well, which is another advantage of this method.

\section{Appendix A}

This appendix describes the processes of the GA, ACO, and PSO. It also illustrates their simulation conditions introduced in the previous sections. 


\section{A1. Ant colony algorithm}

The ACO algorithm presented in (Niknam et al 2005a; Niknam et al 2005b) was employed and simulation conditions are:

Number of colonies: 30

Number of ants in each colony: 10

Evaporation rate $(\rho): 0.9$

Control parameters for determining the weight of trail intensity and length of the path $(\gamma 1$ and $\gamma 2$ ):

$\gamma 2=2$

$\gamma 1=4$.

\section{A2. Genetic algorithm:}

Integer strings instead of binary coding were employed to represent value of the variables, and include these processes (Niknam et al 2005a; Niknam et al 2005b):

- Representation and initialization

- Fitness function

- Reproduction operation

- Crossover operation

- Mutation operation.

Simulation conditions are:

Initial population $=200$;

Selected population $=100$;

Mutation $=4$ Percent;

Crossover probability $=0.7$ to 0.8 ;

\section{A3. PSO}

The original PSO presented in (Niknam et al 2005a; Niknam et al 2005b) was used and simulation conditions include:

Number of swarm $=35$ :

$c_{1}=c_{2}=2 \cdot 0, \omega^{\max }=0 \cdot 9, \omega^{\min }=0 \cdot 4$.

\section{References}

Augugliaro A, Dusonchet L, Ippolito M, Sanseverino E R 2003 Minimum losses reconfiguration of MV distribution networks through local control of tie-switches. IEEE Trans. Power Del. 18(3): $762-771$

Baran M E, Wu F F 1989 Network reconfiguration in distribution systems for loss reduction and load balancing. IEEE Trans. Power 4(2): 1401-1407

Chiou J P, Wang F S 1999 Hybrid method of evolutionary algorithms for static and dynamic optimization problems with application to fed-batch fermentation process. Comput. Chem. Eng. 23: $1277-1291$

Chiou J, Chang C 2005 Variable scaling hybrid differential evaluation for solving network reconfiguration of distribution system. IEEE Trans. Power Syst. 20(2): 668-674

Civanlar S, Grainger J J, Yin H, Lee S S H 1988 Distribution feeder reconfiguration for loss reduction. IEEE Trans. Power Del. 3(3): 1217-1223 
Debaprya D, 2006 A fuzzy multi-objective approach for network reconfiguration of distribution systems. IEEE Trans. Power Del. 21(1): 202-209

Delbem A, Carvalho A, Bretas N 2005 Main chain representation for evolutionary algorithms applied to distribution system reconfiguration. IEEE Trans. Power Syst. 20(1): 425-436

Dorigo M, Caro G D, Gambardella L M 1999 Ants algorithms for discrete optimization. Artificial Life 5(3): 137-172

Eberhart R, Shi Y 2001 Particle swarm optimization: Development, application and resources. IEEE Congress on Evolutionary Computation 1: 81-86

Esmin A, Torres G L, Zambroni de Souza A C 2005 A hybrid particle swarm optimization applied to loss power minimization. IEEE Trans. Power Syst. 20(2): 859-866

Gaing Z L 2003 Particle swarm optimization to solving the economic dispatch considering the generator constraints. IEEE Trans. Power Syst. 18(3): 1187-1195

Gaing Z L 2004 A particle swarm optimization approach for optimum design of pid controller in AVR system. IEEE Trans. Power Syst. 19(2): 384-391

Gomes V, Carneiro S 2005 A new reconfiguration algorithm for large distribution systems. IEEE Trans. Power Del. 20(3): 1373-1378

Goswami S K, Basu S K 1992 A new algorithm for the reconfiguration of distribution feeders for loss minimization. IEEE Trans. Power Del. 7(3): 1484-1491

Hong Y, Hu S 2005 Determination of network configuration considering multi-objective in distribution systems using genetic algorithm. IEEE Trans. Power Syst. 20(2): 1062-1069

Hsiao Y T, Chien C Y 2001 Multiobjective optimal feeder reconfiguration. IEE Proc. Generation, Transmission and Distribution 148(4): 333-336

Huang Y C 2002 Enhanced genetic algorithm-based fuzzy multi-objective approach to distribution network reconfiguration. Proc. Inst. Elect. Eng. 149(5): 615-620

Hu X, Shi Y, Eberhart R 2004 Recent advances in particle swarm. IEEE Congress on Evolutionary Computation 1: 90-97

Kennedy J, Eberhart R 1995 Particle swarm optimization. IEEE International conference on neural networks (NJ: Piscataway) 4: 1942-1948

Kim H, Ko Y 1993 Artificial neural network based feeder reconfiguration for loss reduction in distribution systems. IEEE Trans. Power Del. 8(3): 1356-1367

Li Z, Chen X, Yu K, Sun Y, Liu H 2008 A hybrid particle swarm optimization approach for distribution network reconfiguration problem. IEEE PES General Meeting : 1-7

Lopez E, Opaso H 2004 Online reconfiguration considering variability demand: Applications to real networks. IEEE Trans. Power Syst. 19(1): 549-553

McDermott T E, Drezga I, Broadwater R P 1999 A heuristic nonlinear constructive method for distribution system reconfiguration. IEEE Trans. Power Syst. 14(2): 478-483

Merlin A, Back H 1975 Search for a minimal-loss operating spanning tree configuration in an urban power distribution system. Proc. 5th Power System Computation Conference Cambridge, U.K. $1-18$

Naka S, Genji T, Yura T, Fukuyama Y 2003 A hybrid particle swarm optimization for distribution state estimation. IEEE Trans. Power Syst. 18(1): 60-68

Niknam T, Amiri B 2010 An efficient hybrid approach based on PSO, ACO and $k$-means for cluster analysis. Applied Soft Computing 10(1): 183-197

Niknam T 2010 A new fuzzy adaptive hybrid particle swarm optimization algorithm for non-linear, non-smooth and non-convex economic dispatch problem. Applied Energy Journal 87(1): 327-339

Niknam T 2009a A new hybrid algorithm for multiobjective distribution feeder reconfiguration. Cybernetics and Systems: International Journal 40(6): 508-527

Niknam T 2009b A new hybrid algorithm for multiobjective distribution feeder reconfiguration. Energy Conversion and Management 50(8): 2074-2082

Niknam T 2009c An efficient hybrid evolutionary based on pso and aco algorithms for distribution feeder reconfiguration. European Transaction on Electrical Power (in press) in DOI: 10.1002/etep.339 
Niknam T, Bahmani Firouzi B 2009a A practical algorithm for distribution state estimation including renewable energy sources. Renewable Energy 34(11): 2309-2316

Niknam T, Amiri B, Olamaie J, Arefi A 2009b An efficient hybrid evolutionary optimization algorithm based on PSO and SA for clustering. Journal of Zhejiang University SCIENCE A 10(4): 512-519

Niknam T 2008 A new approach based on ant colony optimization for daily volt/var control in distribution networks considering distributed generators. Energy Conversion and Management 49(12): 3417-3424

Niknam T, Ranjbar A M, Shirani A R 2005a A new approach based on ant algorithm for Volt/Var control in distribution network considering distributed generation. Iranian J. Science and Technology, Transaction B 29(B4): 1-15

Niknam T, Ranjbar A M, Shirani A R 2005b A new approach for distribution state estimation based on ant colony algorithm with regard to distributed generation. Journal of Intelligent and Fuzzy Systems 16(2): 119-131

Olamaei J, Niknam T, Gharehpetian G 2008 Application of particle swarm optimization for distribution feeder reconfiguration considering distributed generators. Applied Mathematics and Computation Journal 201(1-2): 5750-586

Parada V, Ferland J A 2004 Optimization of electrical distribution feeders using simulated annealing. IEEE Trans. Power Del. 19(3): 1135-1141

Prasad K, Ranjan R 2005 Optimal reconfiguration of radial distribution system using a fuzzy mutated genetic algorithm. IEEE Trans. Power Del. 20(2): 1211-1213

Shirmohammadi D, Hong H W 1989 Reconfiguration of electric distribution networks for resistive line loss reduction. IEEE Trans. Power Syst. 4(1): 1492-1498

Taleski R, Rajicic D 1997 Distribution network reconfiguration for energy loss reduction. IEEE Trans. Power Syst. 12(1): 398-406

Tzong S C, Lee C 2003 Network reconfiguration of distribution systems using improved mixed-integer hybrid differential evolution. IEEE Trans. Power Delivery. 18(3): 1022-1027

Zhou Q, Shirmohammadi D, Liu W HE 1997 Distribution feeder reconfiguration for service restoration and load balancing. IEEE Trans. Power Syst. 12(2): 724-729

Zhu I Z 2002 Optimal reconfiguration of electrical distribution network using the refined genetic algorithm. Elect. Power Syst. Res. 62(1): 37-42

Vanderson F G, Carneiro S, Pereira J L R, M P V, Garcia P A N, Ramos Araujo L 2005 A new heuristic reconfiguration algorithm for large distribution systems. IEEE Trans. Power Syst. 20(3): 1373-1378 